\title{
Senso comum e Ciência: uma análise hermenêutica e epistemológica do senso comum de oposição
}

\section{Common sense and science: a hermeneutic and epistemological analysis of the common sense of opposition}

\author{
Ivan Penteado Dourado*
}

\begin{abstract}
RESUMO
O senso comum é um conceito polissêmico, muito citado nas pesquisas educacionais, mas pouco problematizado em relação aos seus desdobramentos na produção de conhecimento científico. A escolha desta definição pode revelar também como se entende a produção do conhecimento. No presente artigo, foi realizado um mapeamento das pesquisas educacionais produzidas sobre o tema do senso comum, em que uma parte das discussões sobre o senso comum é selecionada, reunindo autores que são identificados como pertencentes de uma mesma matriz de entendimento, ou seja, pensadores que opõem ciência e senso comum. Bourdieu, Nunes, Paty e Bachelard, juntamente com outros pensadores fundamentais sobre o tema, são recuperados e analisados teoricamente. Proponho a análise desta categoria por meio de uma hermenêutica sociológica proposta por Boaventura de Sousa Santos, objetivando analisar as consequências sociais para a manutenção dessa postura para a ciência atual. Utilizando a metodologia de revisão bibliográfica, pela perspectiva analítica da árvore conceitual, será possível responder a seguinte problemática: quais os desdobramentos epistemológicos na produção de conhecimento quando as pesquisas optam pela adoção de referências que trabalham com o senso comum como conhecimento oposto ao pensamento científico? As principais conclusões da pesquisa analítica são que o afastamento do conhecimento científico produzido pela sociedade e um conjunto de dificuldades que as ciências sociais possuem ao realizar
\end{abstract}

* Universidade de Passo Fundo. Passo Fundo, Rio Grande do Sul, Brasil. E-mail: ivan. dourado@acad.pucrs.br. https://orcid.org/0000-0002-4529-831X. 
essa ruptura estariam perfeitamente representadas nas posturas de oposição que esses teóricos mantêm vivas em suas discussões.

Palavras-chave: Senso comum. Hermenêutica. Ciência Moderna. Epistemologia.

\begin{abstract}
Common sense is a polysemic concept, much cited in educational research, but not problematized enough in terms of its developments in the production of scientific knowledge. The choice of this definition may also reveal how the production of knowledge is understood. In the present article, a mapping of educational research on the theme of common sense was carried out, selecting a part of the discussions about the subject, bringing together authors who are identified as belonging to the same matrix of understanding, that is, thinkers who oppose science and common sense. Bourdieu, Nunes, Paty and Bachelard, along with other key researchers on the subject, are retrieved and analyzed theoretically. I propose an analysis of this category through the lens of sociological hermeneutics as proposed by Boaventura de Sousa Santos, aiming to investigate the social consequences for the maintenance of this posture for science currently. Using the methodology of bibliographic review from the analytical perspective of the "conceptual tree", it will be possible to answer the following problematic: what is the epistemological unfolding in the production of knowledge when the researches opt for the adoption of references that work with common sense as knowledge opposed to scientific thought? The main conclusions of the analytical research are the enormous distance from the scientific knowledge produced by society and the fact that a set of difficulties that the social sciences have in achieving this rupture can be perfectly represented in the oppositional positions that the theorists in question keep alive in their discussions.
\end{abstract}

Keywords: Common Sense. Hermeneutics. Modern Science. Epistemology.

\title{
Introdução
}

O senso comum como objeto de reflexão existe desde a origem dos escritos filosóficos. Aristóteles é tido como o primeiro pensador de que temos registro como articulador das primeiras definições de senso comum (senso comunis). Antes dele, Platão, metaforicamente explicou a vida na caverna como uma condição que nos aprisiona no mundo sensível, fazendo-nos crer que a realidade estaria nas sombras projetadas no fundo de uma caverna (PLATÃO, 1964). Para Trindade 
(2001), é possível identificar no mito da caverna uma espécie de desqualificação do senso comum. Na alegoria platônica existiam, de um lado, homens presos na caverna, representando o homem comum e o seu "conhecimento" equivocado e oriundo dos sentidos. Eles construíam, por consequência, falsas imagens para entender e explicar a realidade (imersos no senso comum). Do outro, a figura que se tornará o filósofo, ou seja, um dos poucos homens que conseguiu alcançar outras formas de conhecimento, saindo das sombras e caminhando em direção à luz (TRINDADE, 2001). Dessa forma o senso comum foi, aos poucos, sendo redefinido de "sombras da realidade" para uma falsa compreensão, aproximada de um entendimento ideológico, tal como uma falsa consciência ou ainda uma ilusão de realidade, sem, com isso, deixar de figurar pelas diferentes áreas do conhecimento humanístico como um tema relevante (BOULTER, 2007).

Para compreender o estudo do senso comum como tradição teórica, é possível propor um marco teórico na figura de Thomas Reid (1710-1796). Ele inaugura a escola escocesa do senso comum através de duas das suas mais importantes obras: An Inquiry into the Human Mind on the Principles of Common Sense (2010) e Essays on the Intellectual Powers of Man (2002), como resposta às escolas filosóficas racionalistas e empiristas. Para ele, as fronteiras estabelecidas desde Platão entre o senso comum e o pensamento filosófico influenciariam enormemente a filosofia ocidental (BOULTER, 2007). Porém, essas mesmas fronteiras conduziriam a produção de conhecimento filosófico a um distanciamento da realidade vivida, principalmente no momento em que ela passa a negar a validade do conhecimento de senso comum.

Reid auxilia na definição de um marco inicial na problematização do senso comum como elemento central de investigação filosófica, na qual esse tipo de definição conduz a uma espécie de filosofia da vida cotidiana. O senso comum emerge dentro de uma escola de pensamento como ingrediente central para problematizar o funcionamento da mente no campo de pesquisas filosóficas. Na esteira de Reid, tivemos seguidores de seus princípios, como é o caso do filósofo inglês George Edward Moore (1853-1958), mais precisamente em suas obras intituladas Estudos filosóficos (1967) e Uma defesa do senso comum (1985), além de influências em teóricos posteriores como John Dewey (1859-1952) e Gilbert Ryle (1900-1976) que publicaram diversos trabalhos com inspirações comuns na discussão de Reid.

Nas Ciências Sociais, abriram-se problematizações relacionadas ao senso comum desde os clássicos. Porém o senso comum como referência central nas pesquisas sociológicas destaca-se muito recentemente, em especial com a emergência da chamada Sociologia da Vida Cotidiana. Para José de Souza Martins $(1998,2014)$, referência brasileira nessa linha, as influências que a fenomenologia e a etnometodologia tiveram como protagonistas nesse processo são 
inegáveis. Trouxeram, segundo ele, ricas interpretações sobre o senso comum ao propor um caminho metodológico para o entendimento da realidade vivida. "As descobertas da etnometodologia sugerem que a desordem e a revolta só atingem a ordem superficialmente, pois apenas suprimem significados por um certo tempo, sem atingir o método (de senso comum), o critério, dos procedimentos que reconstituem o tecido rompido" (MARTINS, 1998, p. 3).

Nessa mesma linha, para Garfinkel (1967) e Gouldner (1972), o senso comum seria uma espécie de método de produção de significados, identificando um aspecto positivo dessa definição. Os autores verificaram inclusive que, mesmo em momentos de desestruturação social, como guerras e catástrofes, o senso comum teria a capacidade de produzir novos significados compartilhados, substituindo rapidamente a ausência dos significados destruídos. Pesquisas produzidas nessa perspectiva inauguraram a possibilidade de produção de novas descobertas relacionadas ao estudo da vida comum, do pensamento do cidadão comum. Os pensamentos rotineiros e da ordem do dia emergem, então, como ingrediente essencial para o entendimento da sociedade moderna, inclusive sobre a Ciência Moderna.

$\mathrm{Na}$ busca por mapear a atualidade dessa problemática em diferentes áreas do conhecimento acadêmico, uma grande quantidade de teóricos que lidaram direta ou indiretamente com esse tema emergem com diferentes contribuições. Em uma pesquisa no Portal de Periódicos da Capes $^{1}$, por exemplo, encontrei 1.572 resultados para senso comum, sendo: 1.085 artigos, 341 dissertações e 249 teses produzidas no Brasil.

Após um mapeamento mais específico desses trabalhos oriundos das áreas de Ciências Humanas, observei uma lista das principais referências teóricas citadas nesses estudos. $\mathrm{Na}$ área de pesquisa em educação, por exemplo, se percorrermos o Banco de Teses e Dissertações da Capes, o termo senso comum nas pesquisas aparece 257 vezes entre teses e dissertações ${ }^{2}$, já entre os artigos produzidos disponíveis no portal de periódicos da Capes, apareceram 1.304 artigos publicados na área de Educação; essas pesquisas foram produzidas particularmente na linha das Políticas Educacionais, muito ligadas ao desafio da formação de professores. Portanto, a discussão sobre o senso comum não figura como um tema original, mas como um tema recente nas pesquisas e problematizações no Brasil $^{3}$ a partir do ano 2000.

1 http://www.periodicos.capes.gov.br. Acesso em: 10 jul. 2017.

2 Disponíveis apenas documentos da plataforma Sucupira de 2013 a 2016, atualizada pela última vez em 15 de novembro de 2016 (http://www.periodicos.capes.gov.br).

3 A pesquisa que foi realizada no portal de periódicos da Capes resultou em um total de 39 artigos e cinco livros a partir de uma busca refinada com os termos "políticas educacionais" e "senso comum". A pesquisa foi realizada em 24 de setembro de 2017. 
Na identificação de elementos ainda não problematizados sobre a temática do senso comum, passo a priorizar o entendimento dos teóricos-referência, citados e referenciados nos estudos mapeados. De início, foi-me possível perceber diálogos e pontos interessantes para serem problematizados com o que poderia chamar de uma espécie de clássicos do senso comum no pensamento teórico brasileiro. Ítalo Calvino, em sua obra Por que ler os Clássicos afirma que, "um clássico é um livro que vem antes de outros clássicos; mas quem leu antes os outros e depois lê aquele, reconhece logo o seu lugar na genealogia" (CALVINO, 1993, p. 14). Ou seja, se pensarmos que clássicos são aqueles livros que servem como referência obrigatória para falar sobre algo no campo do conhecimento. Considero, no presente trabalho, como clássicos do senso comum, os pensadores mais citados como referência para discutir o senso comum e as referências que estes últimos dialogaram na construção das suas definições.

Do ponto de vista metodológico, parto para uma análise crítica das principais referências sobre o tema realizando uma análise bibliográfica. Ao invés de filiar-me a uma tradição de pesquisa específica ou de um autor específico, conduzirei a presente discussão a uma vertente, a qual trata o patrimônio teórico como uma espécie de "caixa de ferramentas" (MOUZELIS, 1991, 1995). Incluo, assim, tradições conceituais e teóricas distintas em um mesmo intento de pesquisa para conduzi-las a uma recontextualização, de modo a tornar essas combinações operativas para a problematização de uma realidade social específica. Aproximando-me do que Pires (2007) chama de perspectiva metodológica de "árvore conceitual", o que possibilita erguer, entre outras coisas, novas problemáticas de pesquisa quando elas emergem de choques e reflexões teóricas até então não realizadas. Sobre esse caminho metodológico, Pires (2007, p.11) afirma: "faço-o encarando os seus enviesamentos particulares como qualidade potencial e não como defeito irreparável, pois esses enviesamentos podem ser transformados com proveito em linhas de especificação conceptual”. Essa opção foi, aos poucos, mostrando-se necessária, já que os elementos teóricos, conceituais e documentais que surgiam, ao longo do processo de pesquisa, demonstraram gradativamente a necessidade de não realizar um fechamento epistemológico frente ao tema.

Nesta pesquisa, aglutino posturas epistemológicas mais recorrentes através da criação de categorias de entendimento. Essa estratégia consiste em criar categorias teóricas para pensar a realidade, sem querer dizer que a realidade é assim, mas como uma forma de olhar e pensar sobre ela ${ }^{4}$. Para que a categoria

4 Proposta essa materializada por Emanuel Kant e explicada didaticamente em seu texto intitulado Que significa orientar-se no pensamento? (1985) serviu igualmente de fundamentação para os clássicos das Ciências Humanas na construção de suas propostas teóricas e conceituais. 
realize um recorte mais preciso, proponho definir um intervalo de tempo em que os autores clássicos escreveram as suas obras, problematizando, sobretudo, a relação entre ciência e senso comum e as diferentes definições para o entendimento desse conceito.

Para as pretensões propostas, uma categoria central no presente trabalho será a análise dos autores identificados como pertencentes a categoria de senso comum de oposição. Ela permitirá discutir detidamente as implicações envolvidas em uma das perspectivas mais recorrentes nos clássicos do senso comum, já que, em cada uma, serão agrupados autores que compartilham posturas epistemológicas comuns em relação ao tema. A presente problemática será guia da presente pesquisa, ou seja: quais os desdobramentos epistemológicos na produção de conhecimento quando as pesquisas optam pela adoção de referências que trabalham com o senso comum como oposto ao pensamento científico?

Para refletir sobre essa problemática, será necessário apresentar antes uma matriz interpretativa que permita ampliar o escopo analítico desta postura epistemológica envolvida nessa categoria. Além de agrupar e discutir os seus entendimentos sobre o senso comum, será preciso identificar uma referência capaz de conduzir teoricamente esse diagnóstico crítico sobre os limites e as possibilidades contidas nessa perspectiva. Uma parte das obras de Boaventura de Sousa Santos encaixa-se perfeitamente nessa busca. Resgato aqui, portanto, a sua ambiciosa proposta de submeter às Ciências Sociais a uma análise hermenêutica.

\section{Hermenêutica sociológica e a epistemologia do senso comum}

O pesquisador português Boaventura de Sousa Santos, como autor e/ ou organizador dos livros A crítica da razão indolente (2001), Um Discurso Sobre as Ciências (1987) e, em especial, em sua obra intitulada Introdução a Ciência Pós-Moderna (2000), em que discute o papel da ciência em relação ao saber comum. Logo nas primeiras páginas de sua obra Introdução a Ciência Pós-Moderna (2000), Santos retoma a discussão já apresentada em seu livro anterior chamado Um Discurso Sobre as Ciências (1987), reafirmando o seu diagnóstico da crise que a Ciência Moderna se encontra mergulhada. Identifica, no caso, como seu desdobramento, um conjunto de resultados negativos para a circulação do conhecimento no interior da sociedade, limitado pelo modelo científico moderno. Resultante de um longo período de luta pela autodefinição e institucionalização da ciência como conhecimento de um tipo "superior", constituiu-se numa espécie de modelo fechado em si. Boaventura Santos passa, 
então, a propor críticas pontuais às correntes dominantes das ciências modernas, utilizando a perspectiva hermenêutica de Gadamer (2005), observando os princípios que conduzem o trabalho dos cientistas numa relação interdependente com as disciplinas e pesquisas científicas dominantes.

Objetivo retomar apenas uma parte da discussão, ponderando sobre apenas algumas categorias mais centrais com o intuito de cercar o seu entendimento sobre o papel da ciência moderna hegemônica e a sua relação com o senso comum. Boaventura Santos estará presente na discussão ao oferecer um cabedal analítico hermenêutico sobretudo em relação à tradição de oposição ao senso comum.

A inserção da hermenêutica, proposta por Santos, critica de forma original a ciência moderna, focando no discurso científico e na sua relação com o discurso normal e cotidiano (o senso comum). Propõe, nessa discussão, um recorte muito relevante para as pretensões contidas nesta pesquisa, pois articula o seu eixo argumentativo dentro da área das ciências humanas, dialogando diretamente com o senso comum. Essa aproximação estratégica com a hermenêutica objetiva, segundo ele, "transformar a ciência, de um objecto estranho, distante e incomensurável com a nossa vida, num objecto familiar e próximo, que não falando a língua de todos os dias é capaz de nos comunicar as suas valências e seus limites, os seus objetivos" (SANTOS, 2000, p. 11). Partindo dessa compreensão, justifico a pertinência de retomar a sua proposta chamada hermenêutica sociológica, conduzindo conjuntamente um mapeamento crítico dos processos de produção e apropriação do conhecimento. Segundo aponta, a Sociologia como Ciência Social necessita de uma cuidadosa análise hermenêutica.

Qualquer que seja a opção epistemológica sobre o que a ciência faz, a reflexão sobre a ciência que se faz não pode escapar ao círculo hermenêutico, o que significa, antes de mais, não podermos compreender qualquer das suas partes (as diferentes disciplinas cientificas) sem termos uma compreensão de como 'trabalha' o seu todo e, vice-versa, não podemos compreender a totalidade sem termos alguma compreensão de como 'trabalham' as suas partes (SANTOS, 2000, p. 11-12).

Recuperadas essas questões, voltamos nossa atenção para a apresentação da categoria fundamental para pensar a epistemologia presente nesta concepção de senso comum. Para tanto, a utilização deste cabedal interpretativo de Santos será fundamental. 


\section{Senso comum de oposição}

Após um mapeamento geral das produções relacionadas ao senso comum no Brasil, um conjunto significativo de pensadores que apresentam discussões profundas sobre o tema foram identificados. O senso comum, para um grupo de teóricos, é definido de maneira geral como um pensamento simples e superficial oposto ao conhecimento científico, o que traz à tona elementos epistemológicos importantes e que precisam ser mapeados. A oposição existente entre o pensamento de senso comum e o fazer científico constitui uma das formas discursivas que a ciência utiliza para ganhar força e legitimidade explicativa ao longo de toda a sua história. $\mathrm{O}$ mesmo ocorreu ao longo da história com oposições entre a fé e a razão ou entre instituições como a Igreja e a Universidade etc. O filósofo francês Gaston Bachelard, por exemplo, propõe uma oposição que se aproxima de uma linha bem recorrente entre sociólogos, ou seja, a oposição existente entre ciência e a opinião:

A ciência, tanto por sua necessidade de coroamento como por princípio, opõe-se absolutamente à opinião. Se, em determinada questão, ela legitimar a opinião, é por motivos diversos daqueles que dão origem à opinião; de modo que a opinião está, de direito, sempre errada. A opinião pensa mal; não pensa: traduz necessidades em conhecimentos. Ao designar os objetos pela utilidade, ela se impede de conhecê-los. Não se pode basear nada na opinião: antes de tudo, é preciso destruí-la. Ela é o primeiro obstáculo a ser superado. Não basta, por exemplo, corrigi-la em determinados pontos, mantendo, como uma espécie de moral provisória, um conhecimento vulgar provisório. $\mathrm{O}$ espírito científico proíbe que tenhamos uma opinião sobre questões que não compreendemos, sobre questões que não sabemos formular com clareza (BACHELARD, 1996, p. 18).

Diferente de Reid $(2002,2010)$, não se objetiva travar uma luta contra pensadores que mantiveram essa fronteira ou postura opositiva, mas compreender os pressupostos que os fazem agir dessa maneira e os seus desdobramentos para a produção de conhecimento. Em outras palavras, pretendo dialogar com as oposições, para, posteriormente, superá-las por meio de um mapeamento conceitual mais amplo do senso comum. Esse processo de mapeamento crítico permitirá identificar limites e potencialidades nas definições existentes.

Nesse item, agrupo pensadores que adotam, como postura epistemológica, a oposição ao saber comum, propondo inclúi-los em uma categoria intitulada 
senso comum de oposição. Tentando respeitar os contextos em que se inscrevem as obras e os seus autores, agrupamos, nessa categoria, apenas pensadores que, nas últimas cinco décadas, propuseram perspectivas e entendimentos do senso comum com o intuito de discutir as fronteiras entre a ciência e outras formas de conhecimento. Assim, para discutir essa categoria, Bourdieu et al. (2000), Nunes (1972), Paty (2003) e Bachelard (1996) serão agrupados com o objetivo de discutir as potencialidades e os limites de uma perspectiva epistemológica de oposição.

Outros pensadores são também pertencentes dessa perspectiva opositiva, tal como Gramsci (2004), Saviani (2007) e Benincá (2002). O primeiro, em sua definição de filosofia da vida como sinônimo de senso comum, mas sobretudo na sua hierarquia entre educação assistemática (guiada pelo senso comum) e educação sistemática (alçada ao nível da consciência filosófica) ou de filosofia espontânea ou irrefletida. Em consequência, no caso de Saviani e Benincá, a vinculação direta com a ideia de ideologia, práxis de superação e a discussão proposta sobre a educação - de forte inspiração gramsciana - retiram a possibilidade de contribuir no diálogo que proponho travar com a hermenêutica sociológica proposta por Santos (2000). Dessa forma, as categorias propostas não objetivam agrupar todos os pensadores existentes, mas alguns pensadores chave que nos ajudam a problematizar os limites inscritos nessa postura epistemológica, a qual está sempre em processo de complexificação e aprofundamento.

Essa postura opositiva possui maneiras distintas de constituir-se que se ligam em parte com as linhas teóricas que eles se filiam. Em grande medida, essa postura justifica-se no momento em que consolidam uma estratégia legítima de delimitar as fronteiras do conhecimento científico perante o restante dos conhecimentos existentes, considerados como não científicos, entre eles, o senso comum. Esses autores demonstram a preocupação em revelar nas ciências humanas a existência de objetos e métodos próprios para a produção de pesquisas e, consequentemente, de legitimação dos resultados científicos. Nesse contexto, o senso comum emerge como o seu contrário, ora como um opositor que explica a realidade de forma superficial e sem métodos, ora como um conhecimento que pode ser modificado pela influência direta do conhecimento científico.

Iniciando com a apresentação do mapeamento geral da obra de Bachelard (1996), um conjunto de termos definidores do que entende por conhecimento não científico são utilizados, tais como conhecimento vulgar, sociologia espontânea, ideias vulgares, noções pseudocientificas, conhecimento anterior, tidos por ele como sinônimos do senso comum. De acordo com o estudioso, constituem conhecimentos falsos que necessitariam de uma profunda ruptura para a realização do fazer científico. 
Esse mesmo entendimento é utilizado por Bourdieu no momento em que explica o fazer científico no interior das Ciências Sociais, fundado no que chama de prática da pesquisa sociológica. Na obra escrita por Pierre Bourdieu, juntamente com Chamboredon e Passeron, intitulada Profissão de Sociólogo ${ }^{5}$ (2000), é reconhecida a luta incessante do sociólogo em combater a "sociologia espontânea", já que ela nunca deixará de existir e explicar o real de forma apressada. No decorrer da referida obra, diversos termos são tratados como sinônimos do que chamaram de sociologia espontânea, mas também de opinião comum, noções comuns ou mesmo as pré-noções. Elas carregariam um conjunto de características comuns - ou seja, a ilusão do saber imediato, evidências ofuscantes, sistematizações fictícias - possuidoras de uma riqueza insuperável. Esse conjunto de definições que compõem o senso comum desses autores resultaria num entendimento de que ele seria possuidor de lógicas explicativas de uma natureza inferior, hierarquizando os tipos de conhecimento (BOURDIEU; CHAMBOREDON; PASSERON, 2000).

Seda Nunes, em seu texto intitulado Questões preliminares sobre as Ciências Sociais (1972), apresenta uma longa discussão sobre os descaminhos existentes nas pesquisas e teorizações no interior das Ciências Sociais. Segundo ela, os desafios de construir um corpo teórico e metodológico próprio, suas lutas internas de institucionalização, inúmeras influências de ordem ideológicas, ou das "leituras ideológicas", deixariam as Ciências Sociais muito distantes de outras ciências mais institucionalizadas, tal como ocorre com as ciências exatas e naturais. Essa proposta comparativa entre as ciências e o uso de categorias pejorativas muito comuns na Sociologia Norte-Americana parte de um "ideal" de objetividade positivista, que constitui um traço bem evidente dessa pensadora.

Segundo afirma, a pobreza das Ciências Sociais resultaria em correntes teóricas discrepantes que empobreceriam a produção de pesquisas generalizantes e passíveis de problematizar objetos reais em objetos teóricos precisos e "convincentes" (NUNES, 1972, p. 232). A autora afirma ainda a existência de um tipo específico de epistemologia não científica que se opõe, defendendo uma "distinção sem a qual não nos seria possível escapar aos equívocos e contradições da epistemologia espontânea que recusamos" (NUNES, 1972, p. 204).

Essa matriz positivista e pragmática de Nunes é muito marcante, presente também em sua posição epistemológica em relação ao conhecimento comum. Em muitos momentos, a autora trabalha com o entendimento do senso comum como ideologia ${ }^{6}$ e, como desdobramento dessa relação, identifica-o também

5 Em tradução posterior, a obra foi publicada com o título Oficio de Sociólogo. Petrópolis: Vozes, 2004.

6 Uma referência clássica ao entendimento de Karl Marx, em que a ideologia poderia figurar como uma falsa consciência, retomarei mais detidamente na sequência da discussão. 
como conhecimento vulgar, espontâneo, empirismo ingênuo, não teórico ou pré-teórico. Essa ligação entre senso comum e ideologia permite-lhe relacionar a aquisição do primeiro como ligado a um pertencimento de classe, como definidor da natureza dos elementos e aspectos do real que o indivíduo terá acesso, conforme afirma:

Contra a «evidência» de senso-comum que faz contrastar a «largueza de vistas» dos membros das classes «elevadas» (e «cultas») com a «estreiteza de visão» dos membros das classes «inferiores» (e «incultas»), parece necessário admitir que, sem embargo de a «informação» dos primeiros ser seguramente muito mais densa, isto é: muito mais abundante em «elementos cognitivos», nem por isso a amplitude do respectivo «horizonte» tem de se considerar maior (NUNES, 1972, p. 247).

Essa relação entre ideologia e senso comum pode resultar em uma concepção pré-conceituosa, muito vigente em um passado recente de uma parte considerável dos intelectuais, que permanece presente ainda hoje no interior dos espaços universitários, denominada por Santos como "postura arrogante" 7 (SANTOS, 1987). Essa relação presente nos escritos de Nunes, por outro lado, no momento em que retoma a ideologia para tratar do senso comum, contribui para um tipo de constatação relacionado à inexistência de autores e autorias nos conhecimentos comuns circulantes. Nunes identifica o senso comum como uma forma distinta de "ler o real", na qual ele seria formado por um conjunto diferente dos códigos de leitura realizado, por exemplo, pela ciência. O segundo precisaria romper com o primeiro para constituir-se

essa maneira de «ler» o real - a do senso-comum - e esse «código de leitura» nos sirvam, com elevada eficácia, na nossa existência quotidiana, nada nos diz sobre o seu grau de adequação à estrutura e dinâmica do real. Durante séculos, a Terra, o Sol e as suas relações foram «lidos» como se, sendo a Terra um «objecto» imóvel, [...] e não foi por se ter descoberto ser a Terra que se move sobre o seu próprio eixo e circula ao

7 Em linhas gerais, a postura arrogante apresenta uma crença na existência legítima que hierarquiza e diferencia o saber popular (inferior) e o saber erudito (superior), reforçando a distância entre o que se estuda, o que se pensa no ambiente acadêmico e o que se vive fora dos muros universitários, sendo tradicionalmente considerado o primeiro como mais importante que o segundo (SANTOS, 1987). 
redor do Sol, que a vida quotidiana se alterou. [...] A Ciência, ou antes: uma Ciência, representa uma outra maneira de «ler» o real, diferente da do senso-comum. Implica um outro «código de leitura»; implica, portanto, a construção de outros «objectos», que não os que nos servem para «ler» o real do dia-a-dia. (NUNES, 1972, p. 216-217, grifos da autora).

Essa mesma oposição relacionada ao senso comum é manifesta claramente por Bachelard (1972) em sua proposta de entendimento da história da ciência como um movimento de rupturas epistemológicas. Boaventura de Sousa Santos, no capítulo intitulado "Ciências e Senso Comum" (2000), retoma a proposta de entendimento da ciência dentro da concepção bachelardiana $(1972,1996)$ de rupturas epistemológicas, para, posteriormente, propor uma superação dessa noção. É possível discutir, inclusive, a perspectiva epistemológica adotada pelos teóricos anteriormente apresentados nesta categoria opositiva, que, entre tantas coisas, buscam conjuntamente consolidar o que chamou de primeiro movimento de ruptura epistemológica (BACHELARD, 1972).

Esse processo é de complexa constituição, em especial no caso da Sociologia e, por conseguinte, das Ciências Sociais. Elas apresentam particularidades para consolidar essa primeira ruptura frente aos demais saberes. A "primeira ruptura" constituiria, em linhas gerais, o movimento da ciência buscando constituir-se em clara oposição ao senso comum, ou seja, "a ciência se opõe absolutamente à opinião" (BACHELARD, 1972, p. 14). Santos identifica de forma precisa o que Bachelard chamou de "três actos epistemológicos fundamentais: a ruptura, a construção e a constatação" (2000, p. 33). E no caso específico das ciências humanas, segundo os autores anteriormente mencionados, apresenta uma enorme dificuldade com a realização dessa primeira ruptura por um conjunto de fatores que precisam ser, na sequência, melhor identificados.

Em primeiro lugar, o sociólogo estaria sempre imerso em saberes espontâneos e socialmente compartilhados e o processo de realização desse distanciamento não seria possível de ser realizado completamente. Santos (2000) e Bourdieu et al. (2000) compartilham a enorme dificuldade das Ciências Sociais em consolidar uma vigilância epistemológica, já que tanto o sociólogo está imerso em valores, opiniões e ideologias, quanto o seu próprio objeto de estudos. Bourdieu reconhece que "a maldição das ciências humanas, talvez, seja o fato de abordarem um objeto que fala" (2002, p. 50) e, como diria Piaget sobre a sociologia e a psicologia, e de possuírem "o triste privilégio de tratar de matérias de que todos se julgam competentes" (1979, p. 24).

Boaventura de Sousa Santos (2000) aponta também para uma segunda dificuldade. O próprio cientista social estaria cotidianamente correndo o risco 
de sucumbir à confusão dos resultados de sua investigação com a familiaridade com o objeto estudado. Existe a enorme chance de o pesquisador converter-se em um defensor da "sociologia espontânea", sem muitas vezes ter consciência disso.

Reconheço juntamente com Santos, a dificuldade do pesquisador social em realizar a sua própria vigilância epistemológica, um sacrifício difícil frente ao processo de abandono do senso comum (SANTOS, 2000, p. 35). A análise da categoria epistemológica do senso comum de oposição permitiu até aqui identificar a necessidade da ciência, de cumprir satisfatoriamente essa primeira ruptura, estabelecendo de forma mais clara o seu campo de produção de conhecimento e pesquisa científica, processo chamado por Bachelard de consolidação do movimento de primeira ruptura epistemológica. Sem isso, os resultados das pesquisas e a recepção das teorias seriam confundidos com conhecimentos não científicos, opiniões de pensadores, perdendo, assim, status de ciência. O fato de ser ainda recorrente a estratégia discursiva de oposição nos teóricos demonstra a fragilidade dessa fronteira, até então precariamente delimitada, explicando, assim, a vigência dessa categoria de oposição.

Santos (2000) busca avançar em relação à compreensão de ruptura epistemológica de Bachelard. Constata que, apesar das variações nas respostas oriundas das pesquisas científicas já realizadas, não existiria espaço para a modificação essencial dos processos e estruturas já consolidadas na e pela Ciência Moderna. Em claro desacordo com essa postura, passa a apresentar os limites do que considerou uma oposição maniqueísta da ciência moderna, em que "o conceito de preconceito é o mais amplo de modo a poder incluir o viés, a pré-noção, a pré-concepção, o pré-juízo, a crença irrazoável, a ilusão, o erro, a distorção, o wishful trinking, a expectativa irrealista etc." (SANTOS, 2000, p. 41). Esse maniqueísmo diagnosticado nessas fronteiras de oposição, hierarquização e simplificação do senso comum, faz com que Santos recupere a crítica de Gadamer em relação à hermenêutica do século XIX:

Por ter negligenciado o papel positivo dos preconceitos ou pré-juízos em todo o processo da compreensão. Os preconceitos são constitutivos do nosso ser e da nossa historicidade e, por isso, não podem ser levianamente considerados cegos, infundados e negativos. São eles que nos capacitam a agir e nos abrem a experiência e, por isso, a compreensão de nosso estar no mundo não pode de nenhum jeito dispensá-los (SANTOS, 2000, p. 42).

Os limites dos dogmas científicos já estariam impostos e os seus efeitos seriam cognitivos, criando barreiras cada vez maiores em relação ao campo 
científico e ao campo social, ou melhor, entre o conhecimento científico e o senso comum. Segundo Boaventura de Sousa Santos (2000, p. 37-38), a realização dessa

ruptura epistemológica bachelardiana só é compreensível dentro dum paradigma que se constitui contra o senso comum e recusa as orientações para a vida prática que dele decorrem; um paradigma cuja forma de conhecimento procede pela transformação da relação eu/tu em relação sujeito/objeto, uma relação feita a distância, estranhamento mútuo e de subordinação total do objecto ao sujeito (um objecto sem criatividade nem responsabilidade); um paradigma que pressupõe uma única forma de conhecimento válido, o conhecimento científico, cuja validade reside na objectividade de que decorre a separação entre teoria e prática, entre ciência e ética; $[. .$.$] um paradigma que desconfia das aparências e das$ fachadas e procura a verdade nas costas dos objectos, assim perdendo de vista a expressividade do face a face das pessoas e das coisas [...] um paradigma que se orienta pelos princípios da racionalidade formal ou instrumental.

Santos (2000) nos auxiliou a demonstrar as sutilezas da oposição entre senso comum e ciência, já que a ciência nunca estaria livre de influências dessa ordem. Nessa oposição radical, tal como ocorre com a oposição entre luz/trevas, consolidou um paradigma que acabou por tratar todo o conhecimento fora dos padrões científicos como conhecimentos inferiores, jogando-os na vala comum do pré-conceito. Esse distanciamento da linguagem, dos resultados e do público pretendido apresenta consequências muito sérias para pensar o quanto a definição de senso comum influencia nos desdobramentos da produção do conhecimento.

\section{Conclusão}

Como resultado do mapeamento desses autores, é possível constatar um conjunto de conclusões que, para as pretensões da problemática proposta, serve para pensar uma categoria clássica do senso comum nacional, chamada, aqui, de senso comum de oposição. A oposição que alguns teóricos apresentam - em especial, aqueles oriundos das áreas das ciências humanas, sobretudo da sociologia e filosofia - faz-se ainda necessária pela enorme dificuldade de estabelecer 
claramente a ruptura desse conhecimento com o saber de senso comum. As razões que se poderia chamar de internas, seja nas influências e armadilhas que a sociologia espontânea coloca e que tanto os sujeitos pesquisados quanto os próprios pesquisadores sociais estão sujeitos cotidianamente, ou mesmo nas dificuldades de consolidação de métodos e técnicas de pesquisa que assegurem um nível mínimo de distanciamento do pesquisador frente ao seu objeto. Assim, as dificuldades que as ciências sociais possuem em realizar essa ruptura estariam perfeitamente representadas nas posturas de oposição que os teóricos, aqui brevemente apresentados, mantêm em suas discussões.

Retomando a compreensão que Santos realiza, quando propõe um diagnóstico de crise da ciência moderna e a sua proposta de realização de um importante estranhamento, que se dá em relação aos resultados das pesquisas científicas e à impossibilidade do público leigo, chamado, por ele, de cidadão comum, de compreender essa linguagem. "A verdade é que, de um ponto de vista sociológico, o discurso científico é hoje, em face do cidadão comum, um discurso anormal no seu todo e, por isso, como já se deixou dito acima, só será compreensível se, perante ele, adoptarmos uma atitude hermenêutica" (SANTOS, 2000, p. 28).

Já o segundo estranhamento dar-se-ia com o agravamento do avanço da especialização dentro das áreas científicas, em que o próprio cientista estaria encontrando dificuldades para compreender o que se passa no interior do que Santos chamou de "Scientiapolis" ${ }^{8 "}$. Se antes o conhecimento científico era de difícil acesso ao cidadão comum, agora, gradativamente a linguagem, os termos e os conceitos tornam-se impossíveis de serem compreendidos também aos seus próprios pares. Talvez, seja possível encontrar, na categoria de senso comum de oposição, um fator explicativo importante relacionado às distâncias que separam o que se produz de pesquisas científicas sobre a sociedade e a real possibilidade de acesso do cidadão comum a esse tipo de conhecimento.

Boaventura de Sousa Santos define a necessidade de problematizar essas distâncias, propondo a transformação do conhecimento científico em prática social de conhecimento. Acompanho com ele um diálogo possível dentro dessa primeira categoria de senso comum de oposição. A análise dessa categoria operatória pelas "lentes" hermenêuticas sociológicas reconstrói a concepção de ciência, "inserindo-a numa totalidade que a transcende" (2000, p. 46). A ideia de usar a ciência contra a própria ciência, propondo limites e consequências futuras para as posturas epistemológicas de oposição, foi aqui realizada. O conhecimento científico nesse modelo transforma-se em conhecimento que não circula de forma democrática, transformando-se em conhecimento privilegiado.

8 Uma espécie de "cidade científica" em que a comunicação entre o que se produz e dá sentido à existência dela estaria em risco. 
"A reflexão hermenêutica tem, pois, aqui um duplo cabimento: tornar compreensível o que as ciências sociais são na sociedade e o que elas dizem sobre a sociedade" (SANTOS, 2000, p. 13).

Assim sendo, torna-se possível no presente trabalho problematizar teoricamente esse processo e, portanto, identificar as rupturas dessas fronteiras que afastam os resultados científicos do pensamento social. Em outras palavras, uma das propostas desta pesquisa consiste em sugerir uma forma de identificar os obstáculos na transformação do que é pesquisado no interior da universidade, em resultados de acesso livre e democrático pelo restante da população.

\section{REFERENCIAS}

BACHELARD, G. La Formation de l'Espirit Scientifique. Paris: Pantheon Books, 1972. BACHELARD, G. A formação do espirito científico. Tradução: Estela S. Abreu. 1. ed. Rio de Janeiro: Contraponto, 1996.

BENINCÁ, E. O senso comum pedagógico: práxis e resistência. 2002. Tese (Doutorado em Educação) - Programa de Pós-Graduação, UFRGS, 2002.

BOULTER, S. The Rediscovery of Common Sense Philosophy. Oxford: Palgrave Macmillan, 2007.

BOURDIEU, P.; CHAMBOREDON, J. C.; PASSERON, J. C. A profissão de Sociólogo: preliminares epistemológicas. 2. ed. Petrópolis: Vozes, 2000.

CALVINO, Í. Por que ler os clássicos? 2. ed. São Paulo: Companhia das Letras, 1993.

GADAMER, H.-G. Verdade e método I: traços fundamentais de uma hermenêutica filosófica. Tradução Flávio P. Meurer. 7. ed. Petrópolis: Vozes, 2005.

GARFINKEL, H. Studies in ethnomethodology. New Jersey: Prentice-Hall, Inc./Englewood Cliffs, 1967.

GOULDNER, A. W. The coming crisis of western sociology. London: Heinemann, 1972.

GRAMSCI, A. Cadernos do Cárcere. v. 2. Edição e tradução: Carlos Nelson Coutinho; coedição: Luiz Sérgio Henrique e Marco Aurélio Nogueira. 3. ed. Rio de Janeiro: Civilização Brasileira, 2004.

KANT, I. Que significa orientar-se no pensamento? Tradução de Floriano de Souza Fernandes. In: KANT, I. Textos seletos. Petrópolis: Vozes, 1985.

MARTINS, J. de S. Uma Sociologia da vida cotidiana. São Paulo: Contexto, 2014. 
MARTINS, J. de S. O senso comum e a vida cotidiana. Tempo Social, Rev. Sociol., USP, v. 10, n. 1, p. 1-8, maio 1998.

MOORE, G. E. Estudos Filosóficos. Coimbra: Atlântida Editora, 1967.

MOORE, G. E. Uma defesa do senso comum. São Paulo: Abril Cultural, 1985. (Coleção Os Pensadores)

MOUZELIS, N. P. Back to Sociological Theory. The Construction of Social Orders. Londres: Macmillan, 1991,

MOUZELIS, N. P. Sociological Theory. What Went Wrong? Diagnosis and Remedies. Londres: Routledge, 1995.

NUNES, S. A. Questões preliminares sobre as Ciências Sociais. Portugal Queluz de Baixo: Editora Presença, 1972.

PATY, M. A ciência e as idas e voltas do senso comum. Scientiae Studia, Associação Filosófica Scientiae Studia, p. 9-26, 2003.

PIRES, R. P. Árvores Conceptuais, Uma reconstrução multidimensional dos conceitos de acção e de estrutura. Revista Sociologia, Problemas e Práticas, n. 53, p. 11-50, 2007.

PLATÃO. Alegoria da Caverna. In: PLATÃO. Diálogos III - A República. Porto Alegre: Globo, 1964. p. 203-208.

REID, T. Essays on the Intellectual Powers of Man. Ed. Derek R. Brookes. Edinburgh: Edinburgh UP, 2002.

REID, T. An Inquiry into the Human Mind on the Principles of Common Sense. Syracuse: Ed. Jonathan Bennett, 2010.

SANTOS, B. de S. Um discurso sobre as ciências. 13. ed. Porto: Afrontamento, 1987.

SANTOS, B. de S. Introdução a uma ciência pós-moderna. 3. ed. Rio de Janeiro: Graal, 2000 .

SANTOS, B. de S. A crítica da razão indolente: contra o desperdício da experiência. 3. ed. São Paulo: Cortez, 2001.

SAVIANI, D. Educação: do senso comum à consciência filosófica. 17. ed. rev. Campinas: Autores Associados, 2007.

TRINDADE, A. Ciência e senso comum: uma reflexão ilustrada por comentários sobre o filme O Carteiro e o Poeta. Pró Ciência, São Paulo, 29 de julho de 2001. Disponível em: <http://www.prociencia.com.br/default.htm>. Acesso em: 10 jan. 2016.

Texto recebido em 25 de dezembro de 2017.

Texto aprovado em 12 de fevereiro de 2018. 
